\title{
Analysis on the Fear When Facing Death
}

\author{
Wooster School, Danbury, Connecticut, 06810, US \\ Corresponding E-mail : angela@cas-harbour.org
}

Shengxuan Sun

\begin{abstract} style.

Keywords: death, fear, philosophy, Socrates, Zhuangzi

\section{INTRODUCTION}

It is a universal and painful truth, which people tend to cope by hiding it into their deepest subconsciousness, that all the lives will come to an end. People have fear of death since it symbolizes the biggest unsolvable uncertainty in our lives. However, the degree of acceptance of death can greatly impact perspectives on living in the present. Thus, it is helpful and necessary to realize the imminence of death and learn how to work with this fact rather than to avoid it. In order to do so we need to realize: what will happen after death is limited to two possibilities, the process of dying is not as we imagine, and the sorrow from the death our loved ones can be overcome through reasoning.
\end{abstract}

Why death is not as scary as it sounds ? This is the question this paper attempted to answer. To do so, the paper discusses the problem from three aspects. First, the two possibilities about what will happen after we die. Second, the wrong image in our mind for the process of dying. Third, fear of losing loved ones. Through the discussion from these aspects the paper arrived at a conclusion that death should not be a fearful topic to reflect on. Readers, by realizing this idea, will be able to live at present which will then lead to a more productive life

\section{THE FEAR OF THE LIFE AFTER DEATH}

According to Greek philosopher Socrates, that even though there will not be a definite answer to what will happen after we die, there are ultimately two possibilities: either we will be in dreamless eternal sleep or we will receive the passage to another life [6]. These two possibilities are the basis of our fear of death. Yet these fears should be alleviated if this question is considered rationally and seriously.

The first possibility, which is a passage to another life, should not, in and of itself, evoke fear. In Socrates' view, the other world will be like ours except people will no longer possess a physical body. Some other religious references may describe this stage differently. Some religions consider the afterlife to be in a garden where people are always satisfied, while others describe it as samsara where we will be born again. There is a similarity among these views: death is not an ending - it is just a beginning to another life or a different phase. The next phase may be even better than the one we currently have. Thus, we should not be afraid but be hopeful for the afterlife.

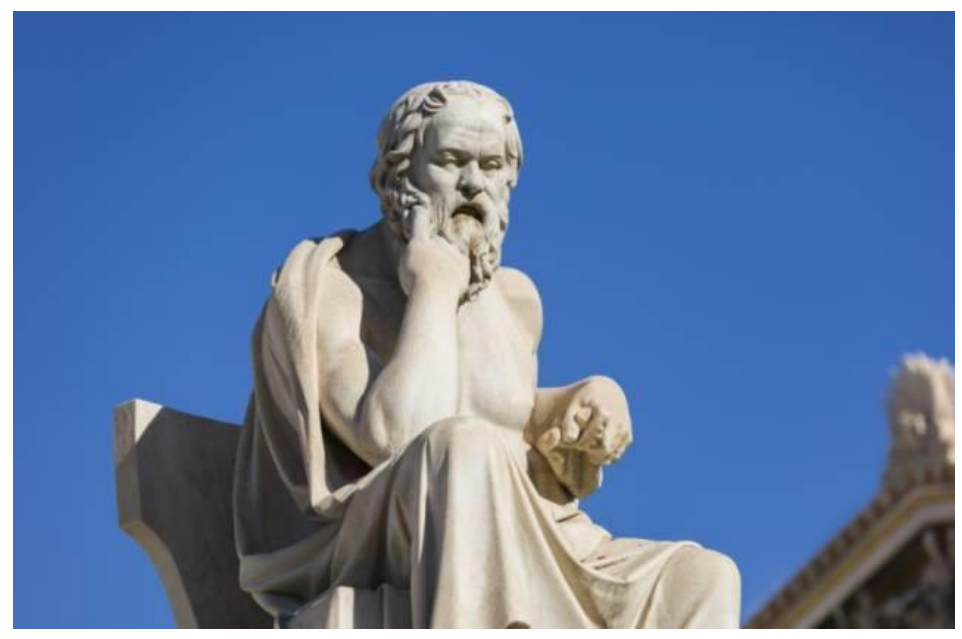

Figure 1. Sculpture of Socrates[7] 
The second possibility - eternal sleep - may be fearful to people for that it symbolizes a feeling of nonexistence. Humans are born with various sensations such as the ability to smell, to see and so on. Our lives are tightly bounded with these abilities. We use them to make sense of the world. But when we die, we think we will lose all these innate gifts of perceptions. At least, we infer that from viewing dead bodies that do not utilize any of their sensory tools. However, according to philosopher Epicurus, sensations only make sense when we are alive[5]. He argues that our lives are strictly limited by our sensations. We determine the nature of our environment, such as what is good or bad, from our sensory organs. In order to possess such sensations, we need to have a living, breathing body. Whereas when we die our body will shut down forever and eventually begin to decay, we will not be able to have the feelings about nonexistence since we will not have a body to possess sensations which can determine the status of our mind and body. As which Epicurus said to himself: "Death does not concern us, because as long as we exist, death is not here. And once it does come, we no longer exist."[2] In order to better understand this concept by Epicurus, consider this scenario: Life and death are two opposites like north pole and south pole which are on the two extreme sides of earth. Feelings, emotions, body forms which we possess when we are alive are at the north pole, and death itself is at the other side - south pole. Therefore, in this way, the process from life to death is the same process as walking from north to south pole, and during this process we gradually abandon all sensations which we had back in north pole when we were alive. Thus when we finally arrived at death all we have to face is the death itself instead of suffering from sensations which we already abandoned on the way.

\section{THE FEAR OF THE PROCESS OF DYING}

Beside the fears about what might happen after death, some may also fear the period before or the process of dying. As portrayed by our society, the final period of our life is often filled with despair.Nevertheless, the end of our lives may not be as universally bad as we think. A study published in 2017 suggests that instead of living in the fear that comes from the denial of death, people should learn to accept death and make their life meaningful. The study analyzed blogs by patients suffering from fatal diseases. They compared the result with a group of participants who were asked to imagine they only have a few months to live and blog about their feelings. [3]Surprisingly, the terminally ill tended to have more positive words in their blogs posts. Conversely, those who were imagining their "illness" had significantly more negative things to say about their "coming death". This comparison shows that instead of becoming more and more fearful as they come closer to death, terminal ill patients learned to accept their inevitable fate and that they do not have much time left to mourn. These patients were able to live comparatively less fearful when facing death due to the fact they could see through the unpredictability: they knew the cause of their death and they had more time to process it. Through this processing of death in their mind, these patients "got used to the idea of dying, like we get accustomed to many things. The initial shock after receiving a poor prognosis is horrific, but after months or years of living with this knowledge, the dread subsides" [3]As people who are fortunate enough to be healthy, we can also try to apply the same thought process which the terminal ill patients use. Instead of imagining the eventual processing as painful and pretending it not to exist, we should realize early in our life that as horrible as death may seem, we need to accept its value of existence. Death will no longer be an incubus that will keep us from cherishing the present. Instead it will become a source of motivation that will urge us to make the best of what we are gifted - life.

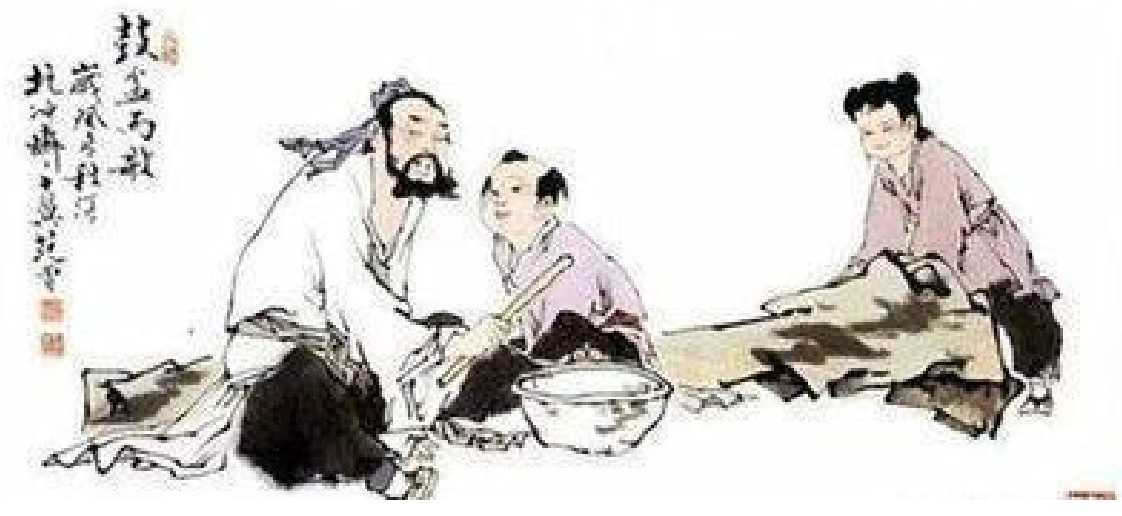

Figure 2. An artwork describes the scene that Zhuangzi celebrated the death of his wife[8].

\section{THE FEAR OF THE LOSS OF OTHERS}

Finally, people may argue that they are fully capable of accept their own death, but what they cannot bear is to witness the loss of their loved ones. Fortunately, this fear can also be overcome through philosophical reasoning. Humans are emotional animal. Thus, when we lose the ones we 
reaction may seem extreme, but when analyzed it explains his fearless attitude towards death. He treats life as a journey and within this journey there is death. There are many changes which will all inevitably happen whether we want to or not. Everyone has to experience these changes alone. Just like parents watching their children grow up from toddlers to adults, the only thing we can do is to accept these changes. We have no right to take away death in one's life, just like we have no right to take away one's life. In sum, there is no point to fear the death of our loved ones, instead we should treat it just as another change in their life. We need to think of their death as a new starting point to a beautiful journey and all we can do is to encourage them to go on to this journey themselves.
Therefore, he should be happy for her just like he was happy for all other changes in her life[1]. The reaction of Zhuangzi

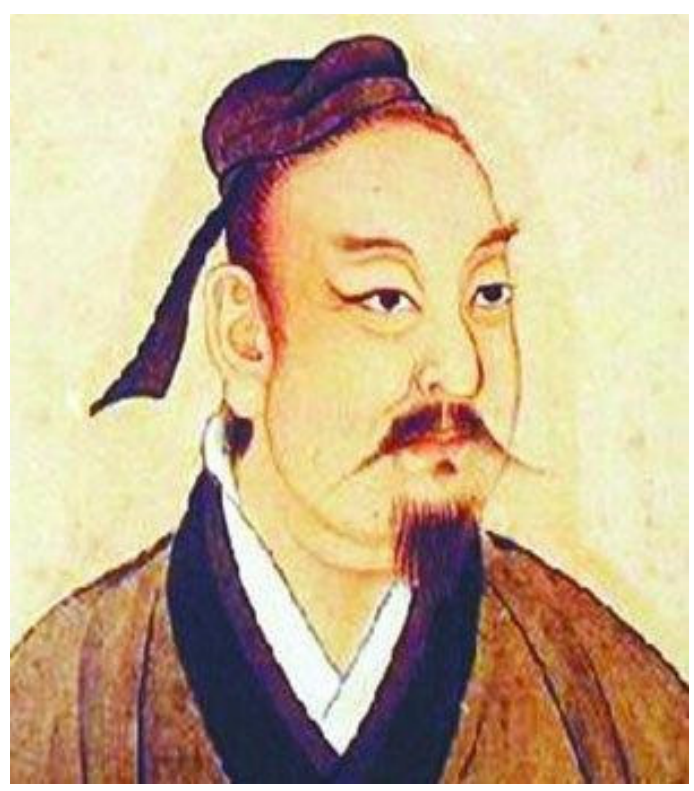

Figure 3. The portrait of Zhuangzi[8].

be ever glowing though our body will decay and eventually will be like dust on the ground. We will be still living, maybe in the memories of the ones who miss us, maybe we will become part of the soil and contribute to the great ecosystem, or maybe there are really heaven and hell that will contains according to god's will. Therefore, author does not fear death for I believe death is not the end, it will only be a starting point to another form of life where he will either receive eternal life or the chance to start a new life. As Thomas Edison's last words state "It is very beautiful over there". Like all the others, the author has no definite answers for the question, what will come after we die. Yet the author is willing to held the belief that the eternal peace will follow the gone of life. 


\section{ACKNOWLEDGMENT}

First and foremost, I would like to show my deepest gratitude to my teachers and professors in my university, who have provided me with valuable guidance in every stage of writing this thesis. Furthermore, I would like to thank all my friends and roommates for their encouragement and support. Without all their enlightening instruction and impressive kindness, I could not have completed my thesis.

\section{REFERENCES}

[1]"Zhuangzi Loses His Wife." Consolatio, Consolatio , 19 Apr. 2005, retrieved on 24. Dec. 2019. https://www.consolatio.com/2005/04/zhuangzi loses .html.

[2] Les Belles Lettres English. "Epicurus: The Nature of Death and the Purpose of Life." Ancient Wisdom for Modern Minds, 2018, retrieved on 24. Dec. 2019. classicalwisdom.com/people/philosophers/epicurus-thenature-of-death-and-the-purpose-of-life/.

[3] J. Brown, "We Fear Death, but What If Dying Isn't as Bad as We Think?" The Guardian, Guardian News and Media, 25 July 2017, retrieved on 24. Dec. 2019. www.theguardian.com/science/blog/2017/jul/25/we-feardeath-but-what-if-dying-isnt-as-bad-as-we-think.

[4] J. Green, Looking for Alaska, Turtle back books, Washington, Sydney, 2006

[5] T. Keefe, "Epicurus." Internet Encyclopedia of Philosophy, retrieved on 24. Dec. 2019. https://www.iep.utm.edu/epicur/\#SH5g.

[6] T. Connolly, "Plato: Phaedo ." Internet Encyclopedia of Philosophy, Internet Encyclopedia of Philosophy, retrieved on 24. Dec. 2019. https://www.iep.utm.edu/phaedo/\#SH3a.

[7] R. F. He, "Socrates: The Road to the Good" Journal of Sichuan University. Philosophy and Social Science Edition, April 1996, retrieved on 8. Jan. 2020. https://www.sohu.com/a/270624166 237819

[8] Interesting Chinese Study, "Zhuangzi's wife died, Zhuangzi sang and sang, was Zhuangzi schizophrenic?" 16 August 2019, retrieved on 8. Jan. 2020. https://baijiahao.baidu.com/s?id=1642009909307252584\&w $\mathrm{fr}=$ spider $\&$ for $=\mathrm{pc}$ 